\title{
Developing Computer-Based Design Approach to Foster the Architectural Skills of Undergraduate Students in Design Studios
}

\author{
Sarinaz Sari Suleiman, Kholoud Hassouneh and Wae'l Al-Azhari \\ Department of Architecture, University of Jordan, Amman 11942, Jordan
}

\begin{abstract}
The paper discusses the importance of computer as a supporting approach in architecture. This approach is expected to foster the students' design skills in design studios. The approach is an educational tool for tutors that could guide the students and increase their creativity in their design. It considers the concepts and the practice of digital architectural design that influence architectural education. The approach is a catalyst for creativity, experimentation, critical thinking and the sustained growth of creative communities. The core of design studio is the notions, methods and skills of digital architectural design. The instruments used for this research was an investigation that made for the work of the fourth year students designs at the architectural department at University of Jordan, by testing design process and product of students' work: first using manual skills, and then using computer-aided programs. The results revealed that the computer-based design approach was able to foster students' design skills as well as to develop their creativity in design. Ninety-one percent of 44 students were found improved in design process using computer-based approach that depends on computer programs. This was done in design studio by improving students' way of thinking, developing their abilities to direct their own learning and pushing them for new definitions in developing their future work.
\end{abstract}

Key words: Teaching architecture, design studio, computer-aided design programs, design skills, design assessment, design creativity.

\section{Introduction}

The job market in Jordan pushes forward to deliver more skills in digital media. Educators started to rethink and examine architectural education in the light of digital technology. The demands for architects who have computer skills have increased since late 1990s of the last century.

Since then, in the University of Jordan, computer design programs changes gradually become a main tool in design process and presentation, oppositely, free hand sketches and manual tools become limited. The evolution of these changes in western countries has been literate and documented well. However, it seems that this procedure is unrewarded in Jordan and there is a severe lack of research and documentation in

Corresponding author: Sarinaz Sari Suleiman, M.Sc., teacher, research field: teaching architecture. E-mail: s.suleiman@ju.edu.jo. this area [1, 2].

The conventional architectural design studio is primarily based on a multi-disciplinary and multi-layered knowledge fields. Architectural design shows aesthetical skills of designer. Meanwhile, designers should take into consideration structural, mechanical and environmental technology issues, beside social, cultural and psychological behavioral aspects [1].

Digital media as used in design studio can bring important changes to the architectural design process, the design studio praxis, the design outcome and the way in which students envision and describe architecture [2, 3].

Architectural design education produces flexible professionals that are adaptable for the future, by increasing the students' skills in interdisciplinary work and fully integrate information technology $[4,5]$. 
Future architectural education should accept, encourage and function with the signatures of different beliefs, cultures and individuals. The architectural practice and education of tomorrow will not be based on one model or approach but in many models and approaches. In other words, hybridity and multiplicity are the road to the future [4]. What has been missing is the approach and theory to bridging the gap between analog and the digital media. Although we have known that there is a territory lying between them, we have not had the necessary maps to explore it systematically [6].

At this stage, this challenge is methodological and paradigmatic rather than technical as a result, schools find themselves today in the odd situation of having a hybrid productive environment with little or no elaborated pedagogy and theory to deal with it [6].

The paper aims to test the importance of computer programs, as it is taught in Jordan, to help students develop their skill in interdisciplinary work. Other objectives are:

- defining the role of computer programs 3D product (imagining, alternatives, building materials and presentation) and examining the role of computer programs of scale proportion, order and algorithm;

- comparing design process approaches, using computer and manual;

- communicating the design process, in addition to the final result.

\section{Methodology}

A reflection-in-action was done while design is in process. Teaching approach depends on six criteria: authenticity and complexity in methods of assessment; use of summative assessment as the main driver for learning; extensive opportunities to develop and demonstrate learning; rich in formal feedback; rich in informal feedback; developing students' abilities to direct their own learning, evaluate their own progress, and support the learning of others [7]. This could be summarized in:
- defining main points of creativity;

- defining main points of assessment in the design studio;

- data collecting about traditional way of design and computer programs that are used in design;

- making a comparison between designing using traditional way and designing by computer in analyzing student's works in both cases;

- concluding advantages and disadvantages of both cases above.

\section{Hypothesis}

There are two hypotheses below:

(1) Hypothesis 1: Digital media are stronger for design development as they demand higher levels of geometrical definition and abstraction, and the elaboration and coordination of complexity and details;

(2) Hypothesis 2: The levels of creativity and exploratory attitude increase creativity.

\subsection{Creativity Assessment}

Is the design creative or not? A question that always arises while evaluating students' projects. It is hard to find one system that may apply to all projects. Architectural design is based on multi-disciplinary knowledge, which makes it hard to evaluate. Evaluation of students work is the sum of functional, technological and aesthetical aspects.

The concept of "creativity" is broad in scope and difficult to define. Consequently, there is no single, clear indication of how it can be enhanced in a learning environment [8]. Learning and teaching for creativity can be achieved successfully when a teacher understands the nature of their own pedagogical reasoning.

The poetic dimension of architecture expresses itself through the materials that constitute the architectonic event: places, forms, spaces, surfaces, colors, light and symbols. The works of architecture, in fact, reach poetic communicative values through 

Undergraduate Students in Design Studios

the way they became part of a place, the way they discover, interpret and give back its elements and its potentialities, through their spatiality, both external and internal, through the language of the forms they present, through the sensations their surfaces and colors arouse, through the playing of light and shadow, through the expressive tensions, the relations and the cross-references that they determine, through, often, all these things put together [9].

All creative processes require profound previous knowledge of the phenomenon or product to be developed incremental creativity involves long-standing and significant knowledge, ripened through self-reflection, experience and evaluation of the generated elements. The process of evaluating a product once it has been produced generates knowledge, whose accumulation results in the experience proper of design's daily activities [10].

Many artists and architects believe that computer offers creative opportunities, but at least two conditions are necessary for creativity: First, the computer program must offer new possibilities, rather than simply aping existing ones; Second, we must never forget this and the program must be in the hands of an artist who can be creative in the medium [3].

In Rogers and Fasciato's [11] study, they suggest that creativity is an individual characteristic and expression, and hence cannot be assessed. However, Balchin [12] concludes that the best complex composite instrument should assess not only the product, but also the four Ps (product, process, person and press) [13].

King and Anderson, as cited by Kleiman [14], sincerely believe that it is the product that is used to evaluate the personality behind the product, and hence it is the product that needs to be evaluated [13].

\subsection{Design Studio Assessment}

The architecture studio creates a context where active learning occurs through group or individual problem-based projects [15].
Challenge of identifying a problem, defining its limits and developing a creative approach to solve it, aids in the development of reasoned judgment, interpersonal skills, reflection-in-action and critical reflection on practice which forms the basis of architectural education.

Evaluation is essential part of education because it helps instructors to recognize student's learning level and make decisions for further educating steps. It also helps students revising their designing process based on given comments [15].

Studio assessment can be categorized into categories: product, process, technology, reflective practice, person, content knowledge, hard skills, soft skills, technology, learning approach/style, reflective practice, professional and innovative practice, and interdisciplinary collaboration.

Concentrating on the design process itself, rather than only on the end product that encompasses formal properties and techniques, is an excellent way to asset students' work. It is important to adopt a process-centered approach to studio work that results in the integration of both conceptual and practical thinking [16].

The aim of improving and fostering students' skills depends on the design process by analyzing students' skills, pointing out reflection on action notes, assessing students' progress and giving feedback to them [7].

\subsection{Investigation Methodology of the Investigation}

3.3.1 Authenticity and Complexity in Problem-Based Learning

The aim was to give students' project that meets with authenticity and complexity in problem-based learning.

Problem-based learning reflects the way people learn in real life [7, 17]. Authenticity and complexity are inherent in the design project briefs issued to the students of architecture, and reflect true professional practice. An architectural brief is provided for a 

Undergraduate Students in Design Studios

building with a prescribed programme, and students are set the task of providing a design solution of "commodity, firmness and delight". This drive to authenticity is supported by tutor-directed and self-directed research, examples being visits to the chosen site and buildings of relevant typologies, presentations and tutorials by architects and consultants experienced in the building type, and discussions with relevant clients and end-users.

\subsubsection{Portfolio Assessment}

A portfolio is a structured collection comprising evidence and critical reflection on that evidence [7]. Summative assessment is based upon the cumulative output of the preceding weeks of formative assessment and feedback. A portfolio submission is required which, together with the final proposals, collects and demonstrates all the iterative developmental work by the student.

In the submission of the final presentation, students were asked to submit the work of preceding week. This provides us with clear evidence of the student's learning journey. Marking down each stage besides writing down note gives a holistic evaluation of teaching process and learning outcomes.

3.3.3 Opportunities to Develop and Demonstrate Learning

Students are afforded the opportunities on a weekly basis to develop and demonstrate the skills and learning that will be required to complete the summative assessment. Interim reviews are programmed into the curriculum to consolidate the formative assessment protocols. In the second project, the digital presentation (PowerPoint, PDF or similar) provides a structured and current portfolio of the student's proposals: Content may include photographs and computer sketches of the site, materials found in situ, initial sketches, diagrams of sun-paths, prevailing wind directions, site conditions, images of architectural precedents, photographs of scale models, as well as the graphic conventions of architectural communications - plans, sections and elevations.
From time to time, tutorials and reviews are structured with pairs of students, allowing one student to note the key points of the other's review-this can be used to supplement the staff comments. The recording student also benefits from the potential for application of these comments in aspects of their own personal project.

\subsubsection{Formal Feedback Provision}

Formal feedback, from a variety of tutors and practitioners, is provided at intermediate reviews in written form. This practice is being stipulated as part of the students' portfolio submissions [7]. Studio design projects conclude with a final review which will assign relevant feedback to the project learning outcomes as a final summation of the work which needs to be addressed. Tutors provide weekly sheets for the students which stipulate the tasks that the students should address in the week ahead, and benchmark the expected level of progress of students within the cohort. The iterative process of the studio tutorial allows the tutors to monitor the students progress effectively. Any misunderstandings in communications or expectations can be attended to in the following session. The formative assessment and learning strategies are therefore inextricably interlinked, the feedback actively influencing the course of action [7].

\subsubsection{Informal Progress Feedback}

In the past, design tutors have used their professional judgment alone to judge student performance - the "connoisseur" model. However, the use of hidden criteria may not be particularly beneficial to student learning [7, 18].

Two factors are considered critical to the success or otherwise continual formative assessment: firstly, the ability of tutors to communicate implicit assessment criteria explicitly; secondly, tutorials are required to take care in the use of language [7, 19]. Architecture, as with many other subjects, has established a jargon of acronyms, similes, and figures of speech which are familiar to the practitioner, but may be unfamiliar to 
newcomers to the subject area [7].

The tutor must be aware of the unfamiliarity of such language to new students, and endeavor to either explain the principles clearly, or communicate without reliance on specialist terminology. In either case, this will benefit the student, not least in future dealings in the professional arena [7].

\subsubsection{Learning Outcomes}

Defining learning outcomes explicitly gives precise assessment all through design process for tutors and helps students developing their own designs. For this experiment, they are listed as follows:

- reaching and recording context and place;

- developing a solution that is fit to Amman context;

- exploring the nature of internal and external space interaction;

- investigating primary technology and materiality;

- recording the process in sketchbook;

- order and geometry;

- presentation.

\section{Case Study}

\subsection{Definition}

Two different projects were given to the students. The first project (manual-based project) was the design of Jordan Expo computer and the second project (computer-based project) was the design of a four-star hotel. Both of the project sites were chosen in the commercial zone in the city center of Amman where architectural typology is traditional vs. modern. The area of the site for each project is $7,000 \mathrm{~m}^{2}$ and the total project built up area was $5,000 \mathrm{~m}^{2}$.

The program of the first project, Jordan Expo, was defined by tutors: It consists of galleries, theater, administration, services and outdoor facilities. The program of the second project, a 4-star hotel, was restricted by the regulations of Ministry of Tourism in Jordan. The program consists of lobby, multipurpose hall, administration, restaurant, accommodation, services and outdoor facilities.
The experiment was made through 44 students in the 4th year of Architecture Department at University of Jordan.

The design process was divided into site analysis, defining program, concept, preliminary design, design development and final presentation.

In the first project, students were encouraged to focus on manual techniques. Students start by their own concept along with the systematic and scientific analyses of information. Tutors let students design as they got used to. Besides, tutors do a reflection in action when possible. While the second project computer-aided programs were encouraged through design process, students start the first project by their own concept along with the systematic and scientific analyses of information. Then students design an algorithmic order as a base for their design development. They use elementary units of behavior (functions) connected by through rationally defined and measurable relations.

In both projects, issues such as massing, proportion and geometrical definition, composition, materiality, skin, context, access/deliveries, circulation, fire safety, security, details of furniture and climatic passive solutions were clarified and assessed by tutors.

\subsection{Experimental Frame Work}

The experimental framework is shown in Fig. 1.

\subsection{Results}

As a result of comparing the outcome of the two projects using the previous methodology and assessment, the results of the experimental frame work are discussed below.

In the site analysis phase (Fig. 2), 13 students with a percentage of $30 \%$ as percentage were better in manual in this phase; 14 students, around $32 \%$, were equal; while 17 students with a percentage $38 \%$ were better in computer. In this phase, computer and manual seem to give almost equal students understanding of the site constraints (context). Students 


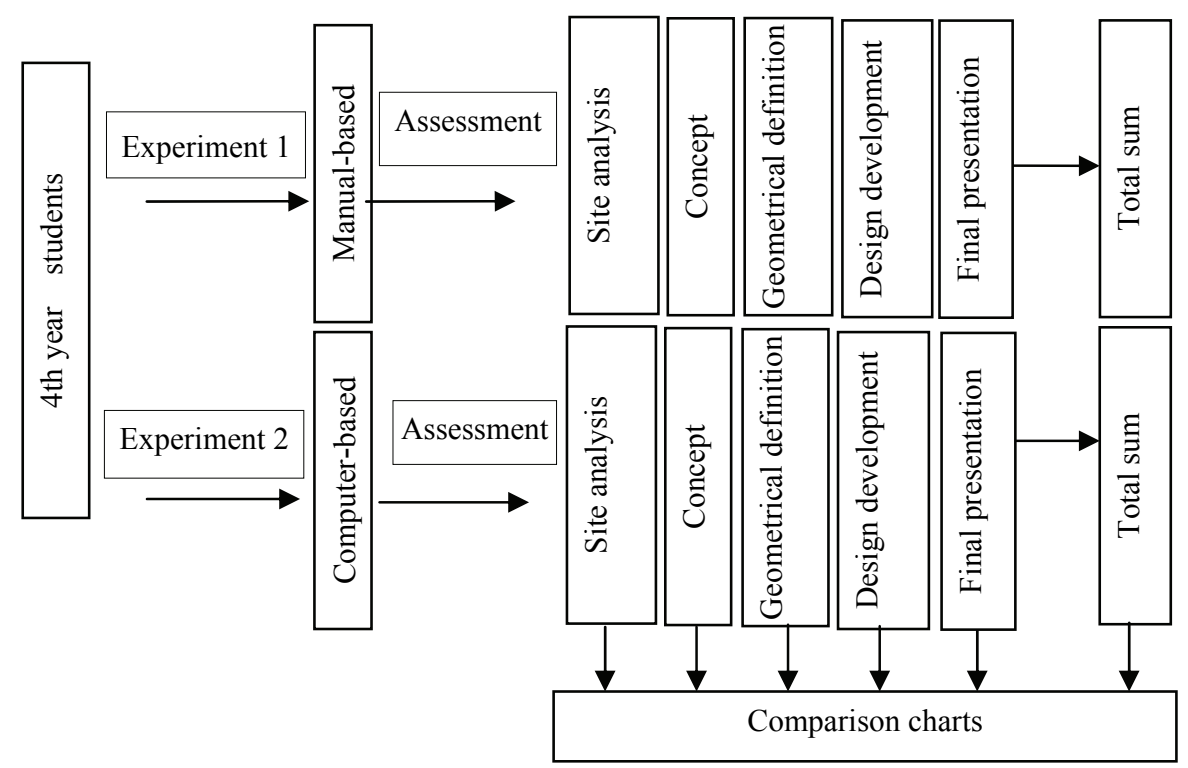

Fig. 1 Diagram shows the experimental framework.

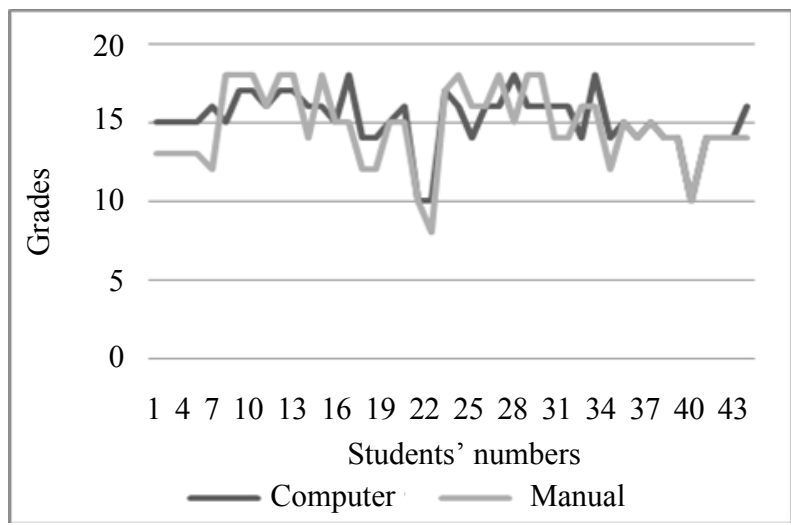

Fig. 2 Students' grades in the site analysis phase assessment.

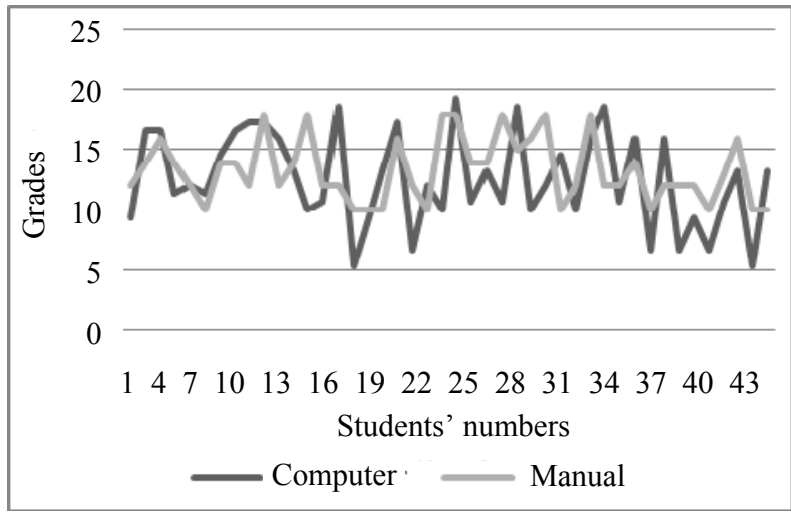

Fig. 3 Students' grades in the conceptual phase assessment.

who were better in manual sketches show better details of the site. While students who were weak in freehand took a benefit from computer programs:
They turned photos into sketches effect.

In conceptual phase (Fig. 3), 59\% of student were better in manual in comparison of $38 \%$ of those in computer and one student of around 3\% remains the same. This indicates that, in this stage, students depend on manual because there are too many design variables to deal with in their mind that are not mature enough.

Fig. 4 shows the geometrical definition phase, a comparison between student marks computer vs. manual skills.

Eight students (18\%) were better in manual than computer, five students (11\%) were the same and 31 students $(71 \%)$ were better in geometrical definition and in generating more complex forms.

In manual-base project, most students tried to do it simple: easy for drawing and take less time. While in the computer-based project, students dare to test more complex geometries.

In the design development phase (Fig. 5), four students $(9 \%)$ got the same grades. They got equal skills both in manual and computer and $91 \%$ were better in design process using computer-aided programs.

In the first project, it was remarked that most students have less numbers of alternative and most of 


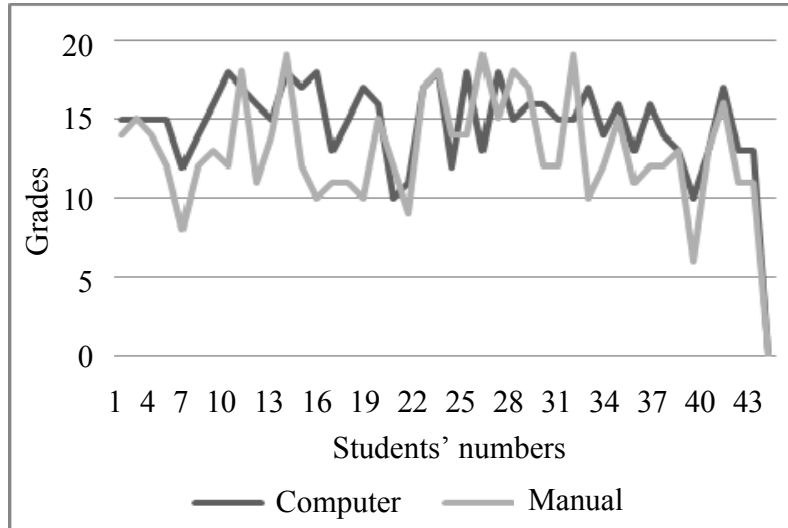

Fig. 4 Students' grades in the geometrical definition assessment.

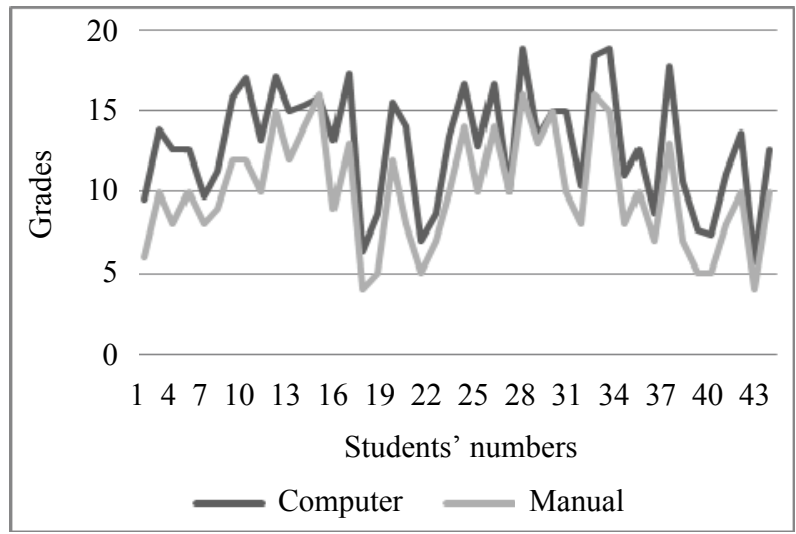

Fig. 5 Students' grades in the design development assessment.

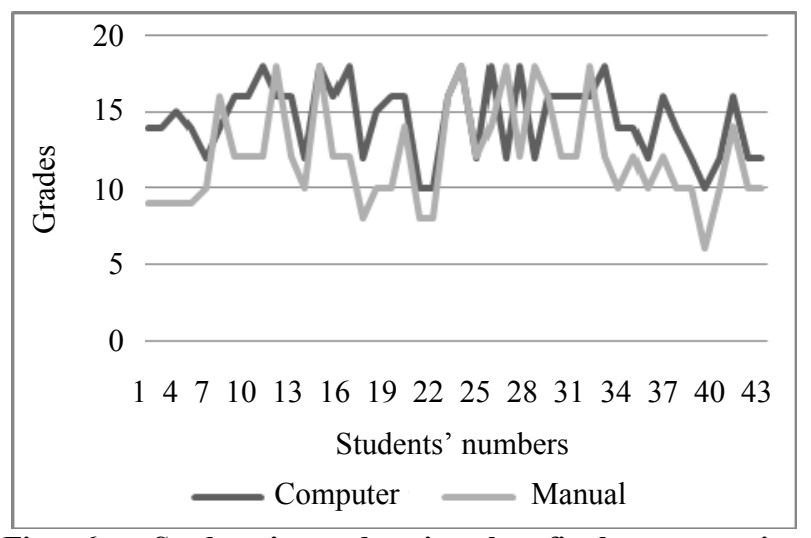

Fig. 6 Students' grades in the final presentation assessment.

them could show tutors just one alternative each class. It was noticed that details in plans were narrowed to wall and openings and there was no time to furnish the plans appropriately. Besides, tutors pointed out that shade and shadow were missed in elevations as well as different building materials. While in the second

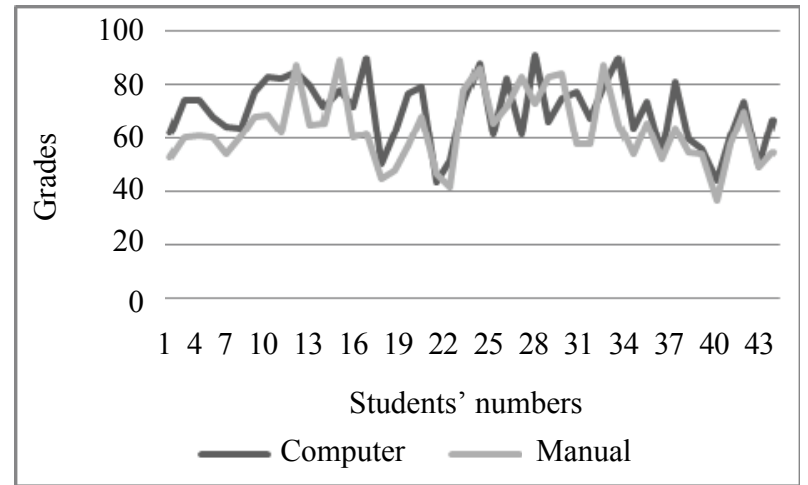

Fig. 7 Students' grades as a total summation of assessments.

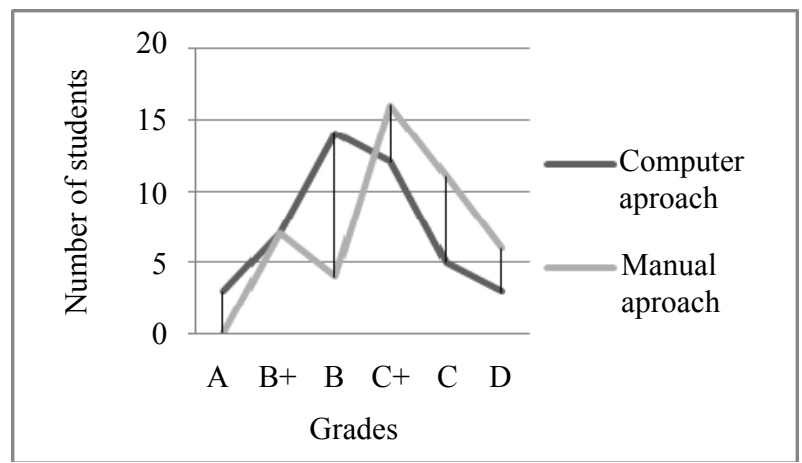

Fig. 8 Shift in students' total grades.

project, computer process, it was obviously noticed the fully detailed furnished plan and sections, besides, it is easy to test different alternative, materials shade and shadow.

In the final presentation phase (Fig. 6), four students $(9 \%)$ were better in manual submission, five students (11\%) got same grades while the rest $80 \%$ were better in computer submission. This shows that computer programs help students to present their intended material, cast shadow, etc. in a fully rendered images. So, the weakness in freehand sketches was overcome.

As a total sum of all the process (Fig. 7), we found that eight students $(18 \%)$ were better in manual skills, half of them with slight difference (only 2 3 grades $1 \%$ ) while 36 students ( $82 \%$ ) were better in computer.

The shift in grades chart (Fig. 8) shows the shift in students' grades that number of students who got better grades increased while $\mathrm{C}+, \mathrm{C}$, and $\mathrm{D}$ grades became less in computer-based process. 
Table 1 Comparison between computer-based project and manual-based project.

\begin{tabular}{|l|l|l|}
\hline \multirow{2}{*}{ Design aspect } & \multicolumn{2}{|c|}{ Computer versus manual } \\
\cline { 2 - 3 } Record context (site analysis) & $\begin{array}{l}\text { Computer-based project } \\
\text { Computer gives (generate) abstract ideas to site } \\
\text { scenes }\end{array}$ & Sketches made student more sensitive to site scenes \\
\hline Main idea concept & $\begin{array}{l}\text { Some students lose it gradually, through } \\
\text { development }\end{array}$ & Most of the students try to keep the outline of it \\
\hline 3D imagining & More (2-3) alternatives & Only one alternative, takes more time and effort \\
\hline Human scale & $\begin{array}{l}\text { Stretching lines can be done easily, most } \\
\text { student lost scale and proportion }\end{array}$ & Human scale under control \\
\hline $\begin{array}{l}\text { Geometric definition } \\
\text { (order and algorithm) }\end{array}$ & $\begin{array}{l}\text { Computer encourage students to test more } \\
\text { complicated module }\end{array}$ & Simple module, equal grid \\
\hline Function in plan & Having more options of solution tone consuming \\
\hline Presentation & $\begin{array}{l}\text { Render materials more clear, students with low } \\
\text { hand quality benefit from computer program }\end{array}$ & Talented students can express better \\
\hline Architectural details & Full details, furniture, landscape, etc. & Less details \\
\hline Submission requirements & Submit all requirement on time & $\begin{array}{l}\text { Missing parts of requirement, such as details, } \\
\text { furniture, and casting shadows }\end{array}$ \\
\hline Feedback & Eye cannot catch all possible comments & All possible comments is in hand \\
\hline
\end{tabular}

\section{Conclusions}

The results above show that about $30 \%$ of students were better in manual skills in the conceptual phase, while $38 \%$ were better in computer skills. On the other hand, more than $70 \%$ were better in geometrical definition and in generating more complex forms using computer. As a result of that, $91 \%$ were better in design process using computer-aided programs and $80 \%$ were better in computer submission.

Depending on the percentages above, the final grades show that $82 \%$ of them were better in computer and getting higher grades.

The paper found out that some students miss order, proportion and human scale when they design using computer, others go in a safe mode by designing using perpendicular grid. To encourage students to be more creative, flexible, and to avoid previous problems, students were asked to reconsider a new dynamic module or algorithmic diagrams. The reflection in action notes that comes out through the design process: to develop a design methodology that helps student to develop their projects by their own reflections, has been summarized in Table 1.

\section{Recommendations}

Today, state of productive and cultural calls for a dynamic equilibrium between the digital and the manual systems of architectural representation. We need both media as each one opens different paraxial territories which are inaccessible by the other. And what is even more important, their interaction generates synergistic opportunities that transcend by far their own individual strengths. The diversity of tools and approaches offers not only more choices but also luminal conditions in the new break through lie. The architectural practice and education of tomorrow are not ahead in the digital but between the manual and the digital, and not in one medium/approach but in many media/approaches. This inclusivity assertion has a strong ideological stand consistent with a humanistic understanding and ethics of architecture.

As this paper has pointed out, what is happening on campus is far more advanced and promising regarding the assimilation of the digital into architecture than what we find in the "real world". In this sense, research on media interaction theory, methodology and pedagogy can play a leading role in guiding our discipline into the future.

\section{References}

[1] Eilouti, B. 2007. "A Problem-Based Learning Project for Computer-Supported Architectural Design Pedagogy." Art, Design and Communication in Higher Education 5 

Undergraduate Students in Design Studios

(3): 197-212.

[2] AI-Qawasmi, J. 2005 "Digital Media in Architectural Design Education: Reflections on the E-Studio Pedagogy." Art, Design and Communication in Higher Education 4 (3): 205-22.

[3] Bryan, L. 2002 "CAD and Creativity: Does the Computer Really Help?.” Leonardo 35 (3): 327-31.

[4] Bermudez, J. 1999. "The Future in Architectural Education." In 87th ACSA (Association of Collegiate School of Architecture) Annual Meeting Proceedings, 321-5. Accessed July 9, 2014. http://faculty.cua.edu/ bermudez/papers/acsa1999-2.pdf.

[5] Hargrove, R. 2011. "Fostering Creativity in the Design Studio: A Framework towards Effective Pedagogical Practices." Art, Design and Communication in Higher Education 10 (1): 7-31.

[6] Bermudez, J., and King, K. 2000. "Media Interaction and Design Process: Establishing a Knowledge Base." Automation in Construction 9: 37-56.

[7] Holgate, P. 2008. "Assessment for Learning in Architectural Design Program." Northumbria Built and Virtual Environment Working Paper Series 1 (2): 194-208. Accessed July 9, 2014. https://www.northumbria.ac.uk/static/5007/bepdf/vollno 2june08.

[8] Corcoran, K., and Sim, C. 2009. "Pedagogical Reasoning, Creativity and Cooperative Learning in the Visual Art Classroom." International Journal of Education through Art 5 (1): 51-61.

[9] Alfano, F. 2003. "The Poetic Dimension of Architecture: Possibilities and Limits in the Teaching of Architecture, Four Faces-The Dynamics of Architectural Knowledge." In Proceedings of the 20th EAAE (European Association for Architectural Education) Conference Stockholm-Helsinki, 1-9.

[10] Luz, M., and Jiménez, N. 2000. "Design's Own Knowledge.” Design Issues 16 (1): 36-51.

[11] Rogers, M., and Fasciato, M. 2005. "Can Creativity Be Assessed?." Presented at the British Educational
Research Association Annual Conference, University of Glamorgan. Accessed July 10, 2014. http://www.leeds.ac.uk/educol/documents/150029.htm.

[12] Balchin, T. 2005. “Assessing Students' Creativity: Lessons from Research." Higher Education Academy April: 1-5. Accessed July 10, 2014. http://www.heacademy.ac.uk.

[13] Eshun, E. F., and de Graft-Johnson, K. G. 2011. "Learner Perceptions of Assessment of Creative Products in Communication Design." Art, Design and Communication in Higher Education 10 (1): 89-102.

[14] Kleiman, P. 2004. "On Assessing Creativity: Some Considerations." The Higher Education Academy. Accessed July 10, 2014. http://www.heacademy.ac.uk/ assets/documents/resources/database/id561_On_assessing creativity_some_considerations.doc.

[15] Hassanpour, B., Utaberta, N., Zaharim, A., and Goh Abdullah, N. 2011. "Students' Perception of the Evaluation System in Architecture Studios." International Journal of Social, Education, Economics and Management Engineering 5 (5): 93-9. Accessed July 10, 2014. http://waset.org/publications/10331/studentsperception-of-the-evaluation-system-in-architecture-studi os.

[16] Ozturk, M. N., and Turkkan, E. E. 2006. "The Design Studio As Teaching/Learning Medium-A Process-Based Approach." International Journal of Art and Design Education 25 (1): 96-104.

[17] Biggs, J., and Tang, C. 2011. Teaching for Quality Learning at University. 4th ed. Maidenhead: Open University Press.

[18] Webster, H. 2001. "The Design Diary: Promoting Reflective Practice in the Design Studio." The Higher Education Academy. Accessed July 10, 2014. http://www.cebe.heacademy.ac.uk/aee/pdfs/websterh.pdf.

[19] Sara, R., and Parnell, R. 2004. The Review Process. CEBE Briefing Guide Series No. 3. Accessed July 10, 2014. http://www.cebe.heacademy.ac.uk/publications/ briefguides/pdf/BriefingGuide_03.pdf. 